\title{
DROP TEST OF A THICK-WALLED CONCRETE CYLINDER SUBJECTED TO SHRINKAGE AND EXPANSION
}

\author{
MASOUD D. CHAMPIRI ${ }^{*}$, M.M. REZA MOUSAVI ${ }^{\dagger}$, MOHAMMAD HANIFEHZADEH ${ }^{* *}$, \\ AREZOU ATTAR ${ }^{\dagger \dagger}$, KASPAR J. WILLAM ${ }^{* * * *}$ AND BORA GENCTURK ${ }^{\dagger \dagger}$ \\ * University of Houston \\ Houston, TX USA \\ e-mail: mdehghanichampiri@uh.edu \\ ${ }^{\dagger}$ University of Houston \\ Houston, TX USA \\ e-mail: mmohammadrezamousavi@uh.edu \\ University of Houston \\ Houston, TX USA \\ e-mail: $\underline{\text { mhanifezadeh@uh.edu }}$ \\ ${ }^{\dagger}$ University of Houston \\ Houston, TX USA \\ e-mail: aattar3@uh.edu \\ $* * *$ \\ University of Houston \\ Houston, TX USA \\ e-mail: kwillam@central.uh.edu \\ $\dagger \dagger \dagger$ \\ University of Houston \\ Houston, TX USA \\ e-mail: bgenctur@central.uh.edu
}

Key words: Drop test, Shrinkage, Expansion, Internal pressure, Failure mode.

Abstract: Two different models including confined cylinder with internal pressure and nonconfined cylinder of a concrete structure are selected for a drop test. With regard to internal pressure, the performance of these structures is compared considering the shrinkage strain which is calculated based on the latest model of RILEM called "B4" (RILEM report, 2014) and expansion which is normally due to alkali-silica reaction (ASR) effect on concrete and calculated based on the substantial experimental study of Larive (1998). The simulations were performed in LS-DYNA, which is suitable for high rate problems in form of explicit time integration. MAT_159 which is available in material library of LS-DYNA is used for the concrete. The failure modes due to the impact of the end drop test are studied. 


\section{INTRODUCTION}

Degradation of concrete limits the service life of structures. Shrinkage due to moisture transfer in the early age of concrete and expansion due to thermal effect and alkalisilica reaction (ASR) may degrade the concrete properties. Thick-walled cylinders are widely used for nuclear containment and the U.S Nuclear Regulatory Commission (NRC) provided some regulations to perform a drop test which are mainly for steel structures [1-3]. From the experimental point of view, usually Digital Image Correlation method (DIC) is used to capture strain [4-7]. A long-thickwalled cylinder is selected to perform some drop tests. Shrinkage strain is calculated based on the latest model of RILEM called "B4" [8] which considers the autogenous shrinkage and drying shrinkage separately. Expansion of ASR gel between aggregate and cement paste reduces the stiffness and strength of concrete and may cause cracking [9-10]. Substantial experimental work was performed by Larive [11] to evaluate the ASR expansion in concrete and a $0.2 \%$ strain after one year was proposed for concrete cylinder specimens.

Many researchers worked on hypothetical events including drop test and free drop test of thick-walled cylinders with different geometries. Gupta [12] proposed a mathematical approach for tip-over simulation. He considered some simple assumptions such as a rigid pad and a single degree of freedom mass-spring system. There are many numerical methods to simulate the behavior of such structures like lattice method and finite element (FEA), while the lattice method is still under development [13-14], FEA approach is more preferred because of its accuracy. Since implicit time integration is not capable of simulating this contact-impact problem due to the convergence issues with regard to the large deformations and rotations and high nonlinearity, explicit time integration is generally used. Teng et al. [15] used a dynamic explicit FEA code, named DYNTRAN for impact analysis of a cask. Elfahal [16] performed an experimental and numerical study to investigate the size effect in normal and high strength concrete cylinders subjected to static and dynamic axial compressive loads. Lee et al. [17] simulated the drop impact of a cask using LS-YNA [18] and ABAQUS [19]. Kim et al. [20] studied shock-absorption of a pad of a cask using ABAQUS explicit. Champiri et al. [21-22] investigated the behavior of a thick-walled degraded concrete cylinder structure under a tip-over event using LS-DYNA.

\section{GEOMETRY AND MATERIAL PROPERTIES}

For this study, a thick-walled cylinder which is about one-third of a prototype structure, has been selected with an external radius of 25 inches $(635 \mathrm{~mm})$, a thickness of 10 inches $(254 \mathrm{~mm})$ and a height of 80 inches $(203.2 \mathrm{~mm})$. The friction-less contact happens on a rigid pad in order to minimize the complexity of this scenario.

A well-known constitutive material model called "MAT_159" which is available in the library of LS-DYNA has been selected to perform this dynamic impact study. Continuous surface cap model (CSCM) relates the shear yield cone and the hardening cap with a smooth intersection. The plastic yield surface corresponds to the initial damage surface. Viscoplastic overstress formulation of Duvaut-Lion is applied to model the rate effects [23]. Figure 1.a shows the behavior of this model under monotonic compression loading for a single unit cubic element with compressive strength of $4.5 \mathrm{ksi}(30 \mathrm{MPa})$. Figure 1.b shows the compression behavior under cyclic loading. As seen, the compressive strength is larger than $4.5 \mathrm{ksi}(30 \mathrm{MPa})$ because of the rate effects, which also changes the slope of unloading/reloading after peak because of the effect of ductile damage that introduces a reduction of the stiffness under cyclic loading. In this material model, rate effects apply to the plasticity surface, damage surface and fracture energy which is based on Simo et al. [24]. Figure 1.c shows the behavior of this material under uniaxial tensile stress. Simple shear is applied to this material model and Figure 1.d shows the shear response. As 
seen, the shear strength is between the compressive strength. There is a kink at a stress of $0.45 \mathrm{ksi}(3 \mathrm{MPa})$ due to transfer from elastic to strain hardening. Mousavi, et al. investigated the behavior of this material model under uniaxial, biaxial and triaxial loading scenarios [25].

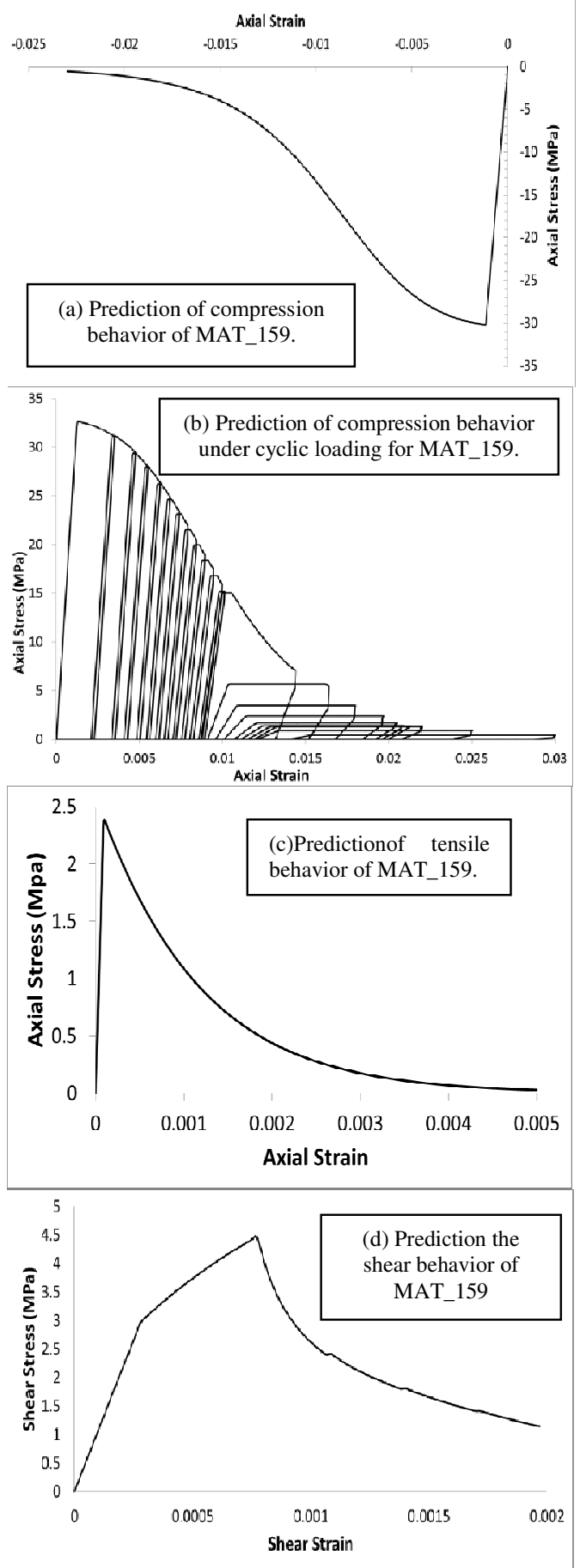

Figure 1:Behavior of MAT_159 under different loading scenarios.
For the drop test, unconfined compressive strength of concrete is selected $5.5 \mathrm{ksi}$ (38 $M P a)$,A Young's modulus of $4192 \mathrm{ksi}$ (28.9 $G P a$ ) and a Poisson's ratio 0.15 is used.

\section{EQUIVALENT TEMPERATURE DUE TO SHRINKAGE AND EXPANSION}

The behavior of this thick-walled cylinder is investigated under shrinkage and expansion. The outer and inner surfaces of the concrete are subjected to negative strains due to shrinkage and positive strains due to expansion of concrete while the other elements are in self-equilibrium.

\subsection{Shrinkage}

The latest formulation of RILEM committee, B4 model [8] has been used to model the shrinkage behavior of the cask. Based on that model, the total shrinkage strain is calculated as

$$
\varepsilon_{\text {sh }, \text { total }}\left(\bar{t}, \overline{t_{0}}\right)=\varepsilon_{\text {sh }}\left(\bar{t}, \overline{t_{0}}\right)+\varepsilon_{\text {au }}\left(\bar{t}, \overline{t_{0}}\right)
$$

where $\varepsilon_{s h}$ is drying shrinkage, $\varepsilon_{a u}$ is autogenous shrinkage. $\bar{t}$ is equivalent exposure duration in days (temperature corrected), and $\overline{t_{0}}$ is equivalent time in days, temperature corrected age at exposure. Final autogenous shrinkage is calculated as

$$
\varepsilon_{a u \infty}=-\varepsilon_{a u, c e m}\left(\frac{a / c}{6}\right)^{r_{\varepsilon a}}\left(\frac{\omega / c}{0.38}\right)^{r_{\varepsilon \omega}}
$$

where $\varepsilon_{\text {au, cem }}$ is autogenous shrinkage in cement, $\omega / c$ and $a / c$ arethe water-to-cement ratio and aggregate-to-cement ratio (by weight) of the concrete mixture, respectively. Drying shrinkage is calculated according to

$$
\varepsilon_{s h}\left(\bar{t}, \overline{t_{0}}\right)=\varepsilon_{\text {sho }}\left(\overline{t_{0}}\right) K_{h} S(\bar{t})
$$

where $\varepsilon_{s h \infty}\left(\overline{t_{0}}\right)$ is the ultimate shrinkage strain, $S(\bar{t})$ defines the time variation of shrinkage, and $K_{h}$ is dependent on RH humidity.

This model has been applied to the thick walled cylinder. Figure 2 shows the behavior of shrinkage strain for 2 years. The following parameters are considered: cement type I, age of loading: 28 days $\left(t^{\prime}=t_{c}=28\right.$ days $)$, age when 
drying begins: $\left(t_{0}=28\right.$ days $)$, relative humidity: $(h=80 \%)$, volume to surface ratio of cask $(V / S=4.44$ in; or $113 \mathrm{~mm})$, cement content: $\left(C=13.6 \mathrm{lb} / \mathrm{ft}^{3}\right.$; or $\left.219.3 \mathrm{~kg} / \mathrm{m}^{3}\right)$, water-tocement ratio: $(w / c=0.6)$, aggregate-to-cement ratio: $(a / c=0.7)$.

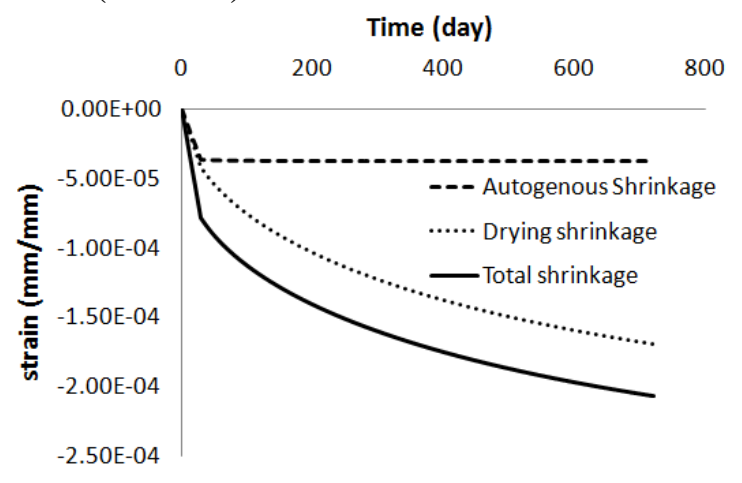

Figure 2:Shrinkage strain within2 years.

\subsection{Expansion}

ASR is one of the chemical attacks that may happen in concrete structures [9]. ASR may cause cracking of the concrete when the ASR gel between the aggregate and cement paste expands. Larive [11] showed that ASR strain can reach to $0.2 \%$ at under different temperature and humidity conditions as shown in Figure 3.

\subsection{Internal pressure}

In order to consider the effect of internal pressure during this test, $0.145 \mathrm{ksi}(1 \mathrm{MPa})$ pressure was applied to the internal layer of the cylinder.

\section{MODELING PARAMETERS}

\subsection{Boundary Conditions}

In the finite element simulations, only half of the cylinder was considered due to symmetry. The displacement component in the circumferential direction of the nodes in the plane of symmetry (X-Z plane) was restrained. The rigid wall was modeled as a frictionless contact to the state of impact.

\subsection{Other parameters}

In order to simulate the drop test, a 10 foot ( 3 meter) free drop of the cask onto a flat was applied. This height is an arbitrary number to see the effects of a high velocity impact. The model has about 20,000 elements and about 23,000 nodes.

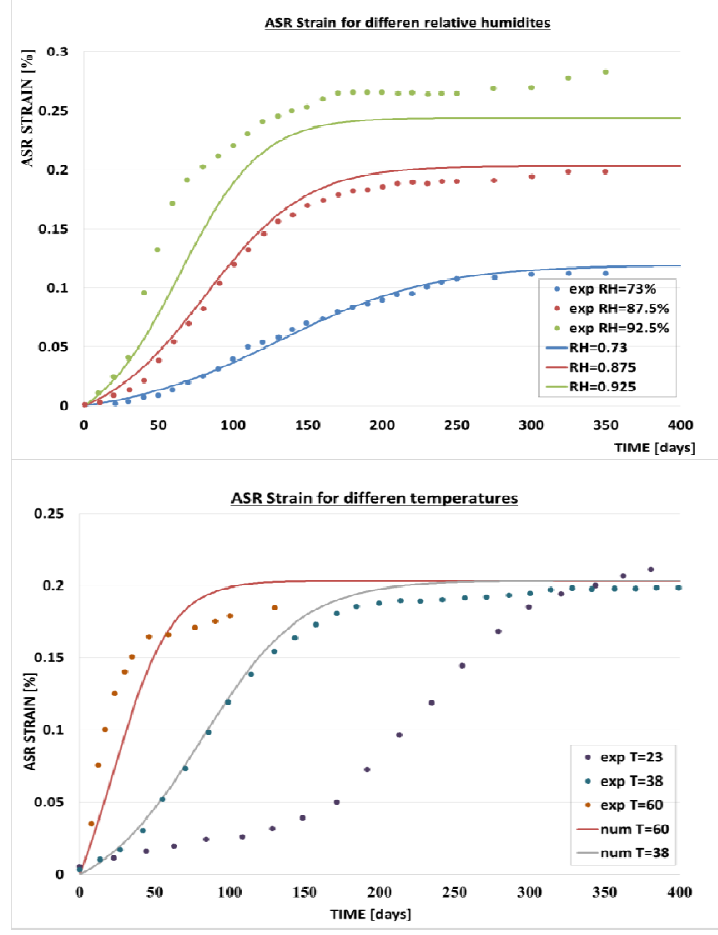

Figure 3:ASR strain at different temperature and humidity suggested byLarive [11].

Total energy reported in LS-DYNA is the sum of: internal energy, kinetic energy, contact (sliding) energy, hourglass energy and system damping energy. In LS-DYNA, internal energy includes elastic strain energy and work done in permanent deformation. External work includes work done by applied forces and pressures as well as work done by velocity, displacement or acceleration boundary conditions.

Hourglass stabilization was considered in this model by using Belytschko-Bindeman [26] (assumed strain co-rotational stiffness form for 2D and 3D solid elements) since one integration point was implemented to evaluate the 8-node brick elements of the 3-D model. This form is available for explicit problems.

Hourglass energy, which is the work done by the forces calculated to resist hourglass modes, takes away from physical energy of the system. Hourglass energy is considered reasonable when it is less than $10 \%$ of total 
energy, so this can be another check point of the accuracy of the model.

Rate effect is another important issue during contact type problems. If rate effect is not taking into account, the response may be different. Rate sensitivity of material was considered for concrete materials during this problem and can be activated directly from MAT-159.

Gravity load was applied to the model as a body load. Internal pressure was implemented as segment load to the internal elements. Shrinkage and ASR strains were imposed to the model in the form of a temperature gradient. To achieve this, a coefficient of thermal expansion (which is assumed here as $\alpha=1 \times 10^{-5}$ was introduced and a corresponding thermal load was applied in the form of a temperature curve. Shrinkage strain was calculated about $\varepsilon_{s h}=-2 \times 10^{-4}$, therefore, the temperature gradient is from 0 to -20 degrees. ASR strain was calculated as $\varepsilon_{A S R}=2 \times 10^{-3}$, which indicates that the temperature is increasing about 200 degrees.

\section{RESULTS}

Seven different cases were considered with regards to material models and for shrinkage, expansion and internal pressure. Energy-time histories, hour-glass force and von-Mises stress contour plots of these cases are compared. The time corresponding to the maximum hour-glass force is selected to present the stress contours in the contact state.

\section{Case 1: Linear elastic material model}

In this case, linear elastic material is considered for the thick-walled cylinder. This case is a benchmark problem and other cases are compared to this case. Figure 4 shows the contour of von-Mises stress in the contact state. Effective stress reaches to $13 k s i$ (90 $M P a$ ) in the lower level of cylinder where the contact happens.

Time histories of total energy, kinetic energy, and internal energy, are presented in Figure 5. It is noted that internal energy suddenly increases at $t=1.15 \mathrm{sec}$ because of contact between the pad and cask. After impact, kinetic energy decreases because of deceleration during contact.

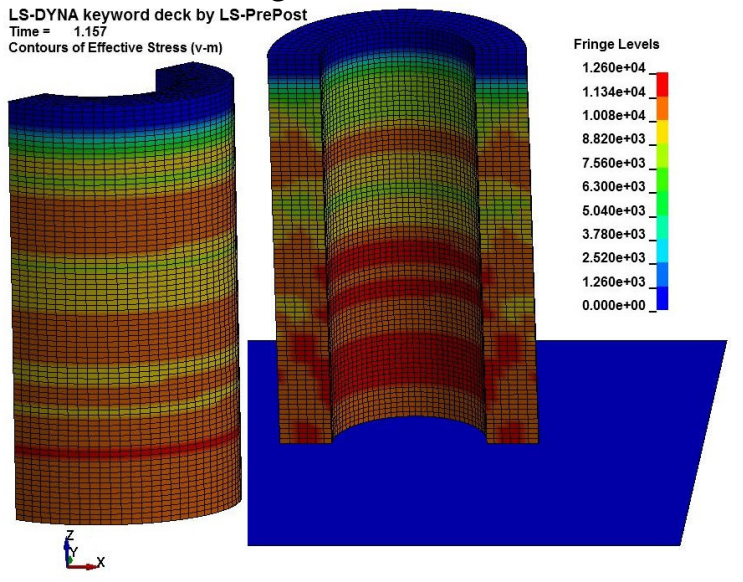

Figure 4:von-Mises stress (psi) contour for case 1.

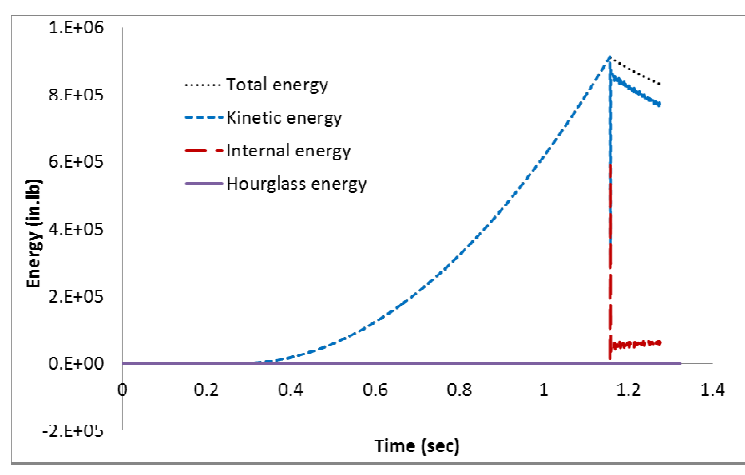

Figure 5:Energy time history for case 1

\section{Case 2: Linear elastic material model with internal pressure}

In case of internal pressure, von-Mises stress increases slightly as shown in Figure 6. Energy time history is same as the previous case.

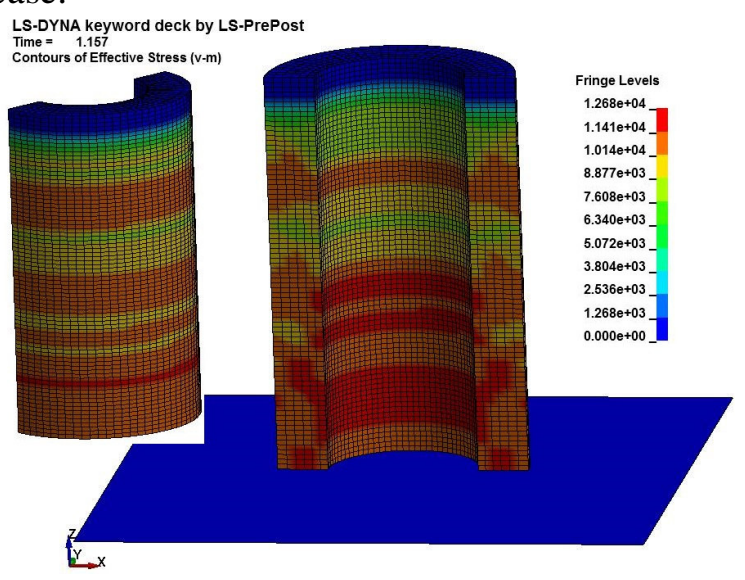

Figure 6:von-Mises stress (psi) contour for case 2. 


\section{Case 3: Non-linear material model}

MAT-159 was implemented for thickwalled cylinder and its behavior was investigated without internal pressure. As shown in Figure 7, von-Mises stress is reduced to $6 \mathrm{ksi}(41 \mathrm{MPa})$ during the impact.

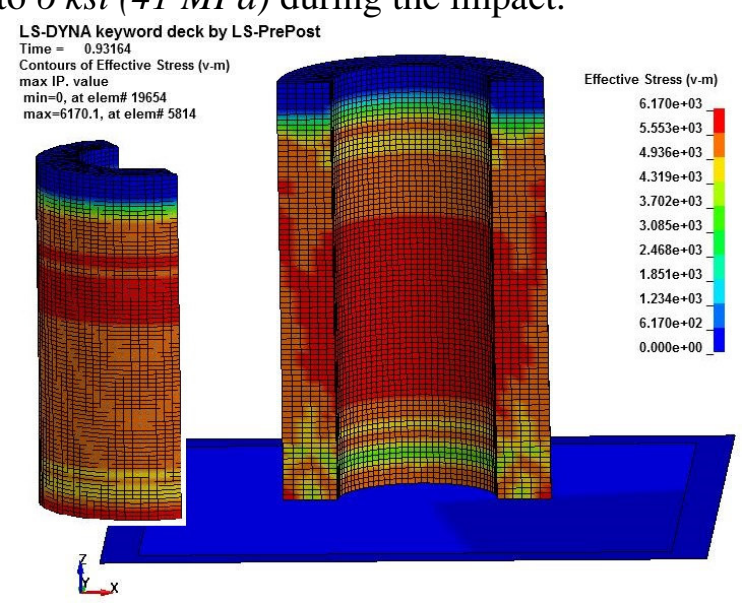

Figure 7:von-Mises stress (psi) contour for case 3.

Time histories of kinetic energy, internal energy and hourglass energy are presented in Figure 8. Hourglass energy is less than 10 percent of total energy.

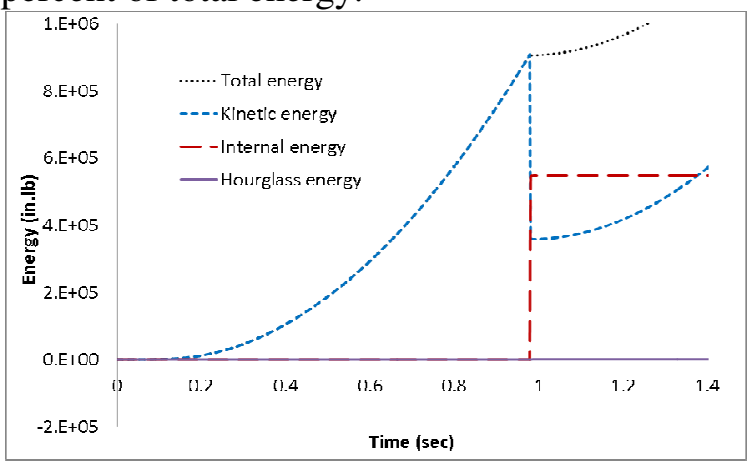

Figure 8:Energy time history for case 3

\section{Case 4: Non-linear material model with internal pressure}

In this case the internal pressure is considered and the behavior of thick-walled cylinder is investigated with non-linear material model. Similar to case 2, stresses and energy levels do not change significantly.

\section{Case 5: Non-linear material model with shrinkage strain}

Shrinkage strain is calculated and implemented in the inner and outer layer of the part as described in Section 4.2. The behavior of the cylinder is investigated considering MAT-159 in case of no internal pressure. As shown in Figure 9, von-Mises stress is reduced to 4 ksi $(27.5 \mathrm{MPa})$ during the impact. It may be said that the concrete sees less shear strain and damage in comparison to previous cases.

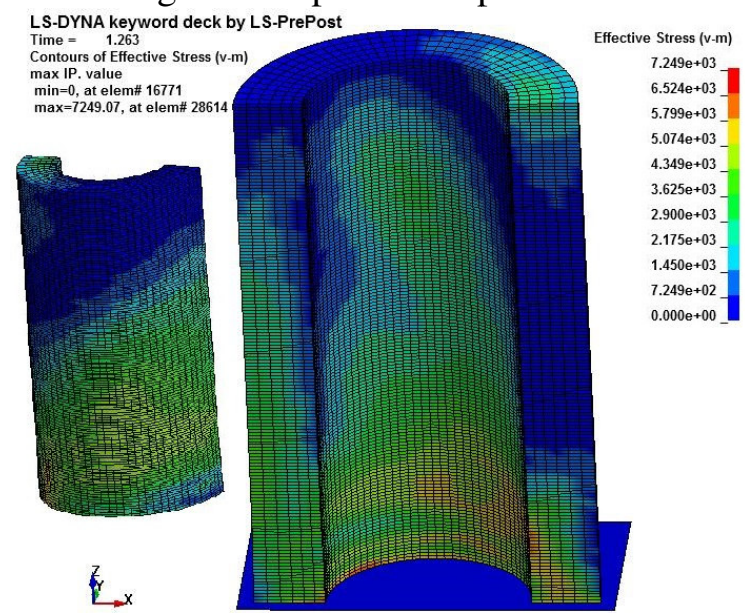

Figure 9:von-Mises stress (psi) contour for case 5

\section{Case 6: Non-linear material model with expansion}

ASR strain is calculated as described in Section 4.2. The behavior of the cylinder is investigated considering MAT-159 without internal pressure. As shown in Figure 10, vonMises stress reduces to less than $2 k s i(14 \mathrm{MPa})$ during impact. Additionally, the energy time histories are plotted in Figure 11,

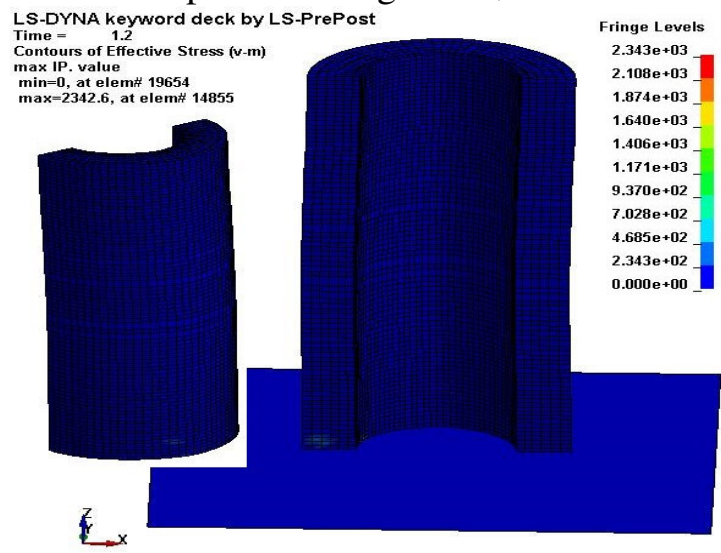

Figure 10:von-Mises stress (psi) contour for case 6. 


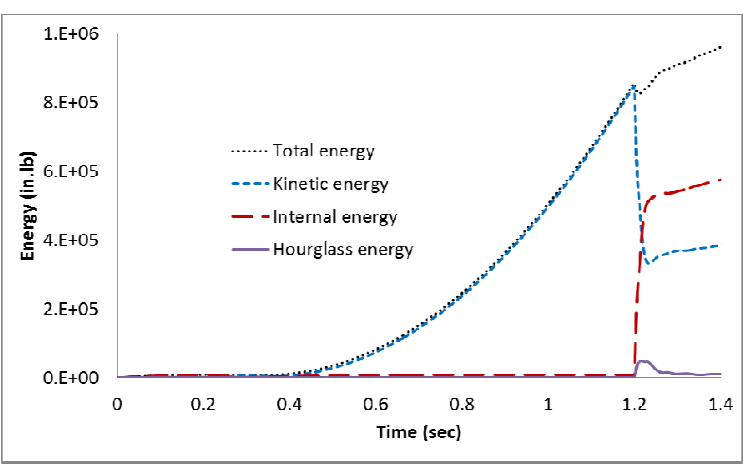

Figure 11:Energy time history for case 6.

\section{Case 7: Failure mode during the impact}

In this case, failure modes of the thickwalled cylinder are investigated. Elements can be deleted in LS-DYNA when they reach a failure criterion. Different failure criteria are introduced as described below.

1) Maximum principal strain. Erosion is initiated when a maximum principal strain is reached according to

$$
\varepsilon_{1} \geq\left(\varepsilon_{1}\right)_{\text {lim }}
$$

where $\varepsilon_{1}$ is the maximum principal strain of an element in a specific time, and $\left(\varepsilon_{1}\right)_{\text {lim }}$ is the limit for maximum principal strain. Once the element satisfies this criterion, it is deleted, can no longer be recovered, and its stiffness will be zero. This is a limit in tension strain and can be applied to brittle materials like concrete and used as a criterion in crack opening. It can also represent tensile fracture and spalling of concrete.

2) Maximum shear strain. Erosion is initiated when a maximum shear strain is reached according to

$$
\gamma_{1} \geq\left(\gamma_{1}\right)_{\lim }
$$

where $\gamma_{1}$ is the maximum shear strain of an element at a specific time, and $\left(\gamma_{1}\right)_{\lim }$ is the limit for maximum shear strain. This criterion can be used for shear failure in concrete elements subjected to contact explosion or close blast loads, or to concrete plates under projectile perforation. The important issue about this criterion is that the estimation of the shear strain erosion limit from concrete is not straightforward.

3) Damage. Erosion is initiated when a damage parameter is reached according to

$$
\mathrm{D} \geq \mathrm{D}_{\text {lim }}
$$

where D is the level of damage in an element at a specific time, and $D_{\text {lim }}$ is the limit for damage. This criterion is highly dependent to the constitutive models used for concrete.

Many researchers used different criteria for failure analysis of structures in finite element software. Mostly, principal strain and shear strain were used for concrete structures, however, tensile damage and tensile stress for evaluation of failure in structures were also considered. An extensive literature review has been performed in order to find a suitable failure criterion for drop test of concrete cylinder in LS-DYNA[27-30].

It was found that using only the maximum compressive strength as an erosion criterion is not a good approach because the stiffness of the structure is highly decreased when the element is deleted, in other words, the stiffness of elements in the softening part is neglected. Therefore, damage based criterion was used. A damage parameter of 0.99 was used. However, it was seen that this criterion cannot capture the shear bond and shear cracks correctly. Therefore, a combination of damage and maximum shear strain was used. Selecting a value for maximum shear strain is not straightforward and it is highly dependent on the material model. A value between 0.1 to 0.9 is widely used in the literature [27-30]. It was concluded that 0.1 can better describe this criterion for MAT_159 (continuous surface cap material model) during this impact problem. Figure 12 show the failure modes of the concrete after impact. As seen in the Figure 12, the dominant failure modes are shear bond, concrete crushing. Additionally, several micro-macro cracks are seen.

\section{CONCLUSIONS}

It is necessary to investigate the behavior of concrete containment structures with degraded material properties to predict their long term behavior. In this paper different cases of impact of a concrete cask were studied using finite element modeling and analyses with linear and non-linear material, internal pressure, and shrinkage and expansion strains. The results were presented in the form of von- 
Mises stress and energy-time histories. It was shown that low rate internal pressure does not change the behavior of structure significantly during impact. Additionally, shrinkage and expansion strain reduce the level of stress during impact. Energy level does not change significantly under different cases while the hourglass energy should be accounted for. Failure modes of the concrete structure were also investigated due to impact and it was found out that concrete crushing and shear bond are the most dominant failures this dropimpact events.

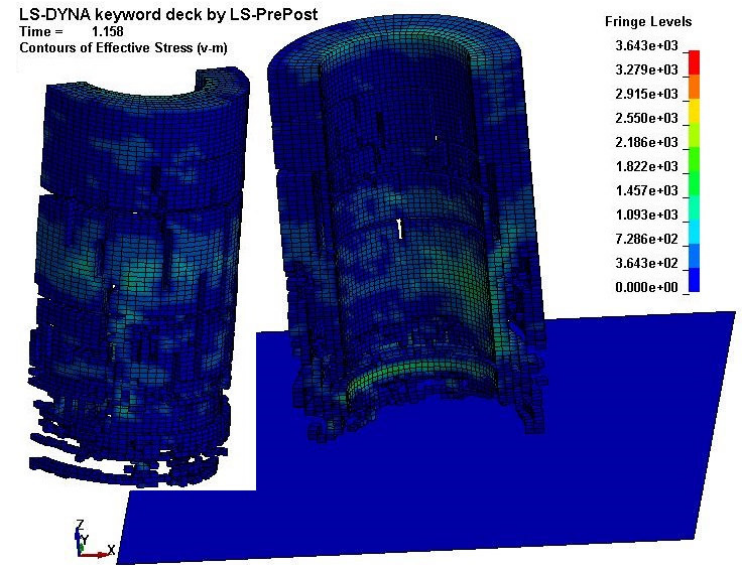

Figure 12:von-Mises stress (psi) contour for case 7.

\section{ACKNOWLEDGEMENTS}

This research was supported by the Nuclear Energy University Program (NEUP), contact number: 00128931. Their support is greatly acknowledged. The opinions expressed in this paper are those of the authors and do not necessarily reflect the views of the sponsor.

\section{REFERENCES}

[1] Nuclear Regulatory Commission (NRC), A Tutorial on packaging and transportation of nuclear materials, Institute of Nuclear Materials Management, Packaging and Transportation Technical Division.

[2] Dilger, F., Halstead, R. J., Ballard, J. D. 2012, Full-scale cask testing and public acceptance of spent nuclear fuel shipments-12254, WM 2012 conference,
February 26-March 1, Phoenix, Arizona, USA.

[3] Halstead, R. J., Dilger, F. 2006, Full-scale cask testing revisited, again, WM 2006 conference, February 27-March 2, Tuscon, Arizona, USA.

[4] Yang, G., Zomorodian, M., Belarbi, A., and Ayoub, A. 2015. Uniaxial tensile stress-strain relationships of RC elements strengthened with FRP sheets. J. Compos. Constr., 10.1061/(ASCE)CC.1943-5614. $0000639,04015075$.

[5] Willam, K.J., Mohammadipour, AH., Mousavi, R., and Ayoub, A. S. 2013. Failure of unreinforced masonry under compression.In Proceedings of the Structures Congress (pp. 2949-2961).

[6] Xotta, G., Beizaee, S., Willam, K.J., 2016, Bifurcation investigation of coupled damage plasticity models for concrete materials, Comput. Methods Appl. Mech. Engrg., 298, 428-452.

[7] Mohammadipour AH, Willam KJ, Ayoub A. 2013. Experimental Studies of Brick and Mortar Composites Using Digital Image Analysis. Proc. 8th Int. Conf. Fract. Mech. Concr. Concr. Struct. Fram., Toledo; Spain. p. 172-81.

[8] RILEM Report. 2014. Report of RILEM committee TC-MDC, Multi decade creep mpdel B4 for concrete creep and shrinkag $e$ including multidecade prediction: descri ption and application, RILEM committee (Bazant,Z. P., Wender, R., Hubler, M. H.)

[9] Champiri, M. D., Mousavizadegan, S. H., Moodi, F. 2012. A Decision support system for diagnosis of distress cause and repair in marine concrete structures, International journal of Computers and Concrete, Techno press, Vol. 9, No. 2, pp. 99-118.

[10] Champiri, M. D., Mousavizadegan, S. H., Moodi, F. 2012. A fuzzy classification system for evaluating health condition of marine concrete structures, Journal of Advanced Concrete Technology, Vol. 10, pp. 95-109. 
[11] Larive, C. 1998. Apports combinés de l'expérimentation et de la modélisation à la comprehension de l'alcali-reaction et de ses effets mécaniques. Monograph LPC , Laboratoires des Ponts et Chaussées, Paris.

[12] Gupta, N.K. 1997.Simplified analytical solution for free drops during NCT for radioactive materials packaging. US DOE report DE-AC09-96SR18500.

[13] Mohammadipour A, Willam K. 2016. Lattice Simulations for Evaluating Interface Fracture of Masonry Composites. Theor Appl Fract Mech, 82:152-68.

doi:http://dx.doi.org/10.1016/j.tafmec.201 6.01.002.

[14] Mohammadipour A, Willam K. 2016. Lattice Approach in Continuum and Fracture Mechanics. J Appl Mech; In Press. doi:10.1115/1.4033306.

[15] Teng, T. L., Chu, Y. A., Chang, F. A., Chin, H. S., and Lee, M.C. 2003. The dynamic analysis of nuclear waste cask under impact loading, Annals of Nuclear Energy, 30, 1473-1485.

[16] Elfahal, M. M. 2003. Size effect in normal and high-strength concrete cylinders subjected to static and dynamic axial compressive loads, Ph.D dissertation, The Pennsylvania State University.

[17] Lee, Y. S., Ryu, C. H., Kim, H. S., Choi, Y. J. 2005. A study on the free drop impact of a cask using commercial FEA codes, Nuclear Engineering and Design, 235, 2219-2226.

[18] LSDYNA software, Livermore Software Technology Corp. - LSTC, $<$ http://www.lstc.com/products/ls-dyna $>$.

[19] ABAQUS software, Dassault systems, $<$ www.3ds.com/productsservices/simulia/products/abaqus/latestrealease $>$

[20] Kim, D. H., Seo, K. S., Lee, J. C., Bang, K. S., Cho, C. H., Lee, S. J., and Baeg, C. Y. 2007. Finite element analyses and verifying tests for a shock-absorbing effect of a pad in a spent fuel storage cask, Annals of Nuclear Energy, 34, 871882.

[21] Champiri, M. D., Attar, A., Hanifehzadeh, M., Willam, K., Gencturk, B. 2015. Longtermperformance of dry storage structures, CONCREEP-10 conference, September 21-23, Vienna, Austria.

[22] Champiri, M. D., Attar, A., Hanifehzadeh, M., Willam, K., Gencturk, B. 2015. Tipover simulation of degraded dry cask storage structures, Proceedings of the ASME $2015 \quad$ International MechanicalEngineering Congress \& Exposition (IMECE15), November 13-19, Houston, Texas, USA.

[23] Murray, Y.D. 2007. User manual for $L S$ DYNA concrete material model 159, Report No.FHWA-HRT-05-062, US department of transportation, Federal Highway Administration.

[24] Simo, J.C, Kennedy, J.G., Govindjee, S. 1988. Non smooth multisurface plasticity and viscoplasticity, Loading/unloading conditions and numerical algorithms, International journal of numerical methods in engineering, Vol. 26, pp. 2161-2185.

[25] Mousavi, R. Champiri, M.D . and Willam, K.J . 2016. Efficiency of damage-plasticity models in capturing compaction-expansion transition of concrete under different compression loading conditions, ECCOMAS 2016 European Congress on Computational Methods in Applied Sciences and Engineering, Crete Island, Greece.

[26] Belytschko, T. and Bindeman, L. P. 1993. Assumed strain stabilization of the eight node hexahedral element, Computer Methods in Applied Mechanics and Engineering, 105, 225-260.

[27] Islam J., Liu Z. and Swaddiwudhipong S. 2011. Numerical study on concrete penetration/perforation under high velocity impact by ogive-nose steel projectile.Computers and Concrete, Vol. 8, No. 1, 111-123.

[28] Shi Y., Li Z-X, Hao H. 2010. A new method for progressive collapse analysis 
of RC frames under blast loading. Engineering Structures, 32: 1691-1703.

[29] Tang E.K.C. and Hao H. 2010. Numerical simulation of a cable-stayed bridge response to blast loads, Part I: Model development and response calculations. Engineering Structures, 32: 3180-3192.

[30] Wu K-C, Li B. and Tsai K-C. 2011. The effects of explosive mass ratio on residual compressive capacity of contact blast damaged composite columns. Journal of Constructional Steel Research, 67: 602612. 